\title{
Determination of harpagoside in Harpagophytum procumbens DC tablet's using analytical method by High Performance Liquid Chromatography
}

Gislane dos Santos Ribeiro ${ }^{(}$, Amanda de Assis Carneiro ${ }^{\circledR}$, Diegue Henrique Nascimento Martins, Luiz Alberto

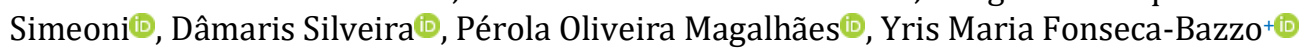

University of Brasília (UnB), Health Sciences School, Department of Pharmaceutical Sciences, Laboratory of Natural Products (LaProNat), Brasília, DF, Brazil

+Corresponding author: Yris Maria Fonseca-Bazzo, Phone: +55 6131071806 email address: yrisfonseca@unb.br

\section{ARTICLE INFO}

Article history:

Received: March 02, 2019

Accepted: November 11, 2019

Published: January 01, 2020.
Keywords:

1. herbal medicines

2. quality control

3. Harpagophytum procumbens

4. devil's claw

\begin{abstract}
The species Harpagophytum procumbens DC is popularly known as devil's claw and is widely used because of its anti-inflammatory properties that are attributed to an iridoid glycoside, the harpagoside. This medicinal plant is part of the Brazilian List of Essential Medicines, that is, it was selected and standardized for the resolution of diseases in the Brazilian public health system (Sistema Único de Saúde - SUS) and can be found in several brands. Due to the importance of quality monitoring, the objective of this study was to create and validate a method for identification and quantification of harpagoside in tablets of the devil's claw, as well as to evaluate the content of this iridoid glycoside in three commercially available brands in Brasília/DF, Brazil. The evaluated parameters in the validation by high performance liquid chromatography were linearity, limits of detection and quantification, precision, selectivity, accuracy and robustness, as required by the Brazilian regulation. The developed and validated method proved satisfactory for the quality control of commercial products that present in this composition the medicinal plant. All the devil's claw brands presented divergences regarding the quality that can interfere with therapeutics and with safety and efficacy.
\end{abstract}

\section{Introduction}

The consumption of herbal medicines grows markedly in developed and developing countries ${ }^{1}$. In Brazil, for example, about $85 \%$ of the population uses some herbal medicine or medicinal plant ${ }^{2,3}$.

Harpagophytum procumbens DC. belongs to the family Pedaliaceae and it is known as devil's claw $^{4}$. The secondary roots of this medicinal plant have been used for centuries for a variety of diseases. From ethnological data, this plant is used in folk medicine to treat fever, arthritis, skin problems, diseases of the digestive tract and as an appetite stimulant ${ }^{5}$. From various studies and clinical evidence, devil's claw is indicated as an anti-inflammatory and analgesic in the treatment of rheumatic diseases, such as osteoarthritis, in 
addition to alleviating the symptoms of acute low back pain, myalgias and other osteoarticular and muscular pathologies ${ }^{5,6}$.

The harpagoside is an iridoid glycoside considered to be responsible for the pharmacological activity of $H$. procumbens DC. This compound is considered the chemical marker of this species. Therefore, it is used as a control to standardize commercial products ${ }^{7}$.

Some factors can compromise the quality of herbal products from the cultivation of the raw material to the final product, such as contamination, the presence of foreign materials, botanical identification errors, among others. These factors result from the lack of care in the collection and identification of the species. Also, adulterations are common to increase the yield of the product. All these factors affect the quality, safety and efficacy of herbal medicines and emphasize the importance of quality control from the cultivation of the raw material to the finished product, as well as phytochemical, pharmacological and toxicological studies ${ }^{8,9}$.

Chromatographic and analytical techniques are used in recognition of the chemical composition, including active principle or toxic compound. These techniques allow the separation and isolation of the substances thus allowing both qualitative and quantitative control of the compounds considered marker of the species. High performance liquid chromatography (HPLC) is one of those techniques widely used for the complete characterization of plant and herbal products, being an important tool in the control of the quality of these products ${ }^{9,10}$.

Pharmacopoeias and monographs are relevant to establish quality standards in addition to standardizing and systematizing knowledge of medicinal plants. These tools present characteristics and properties of plants such as macroscopic and microscopic description, general aspects of the vegetal drug besides identification, purity and assay tests that help in the quality control $^{11}$.

Pharmacopeial methods (for example, in the Brazilian Pharmacopoeia) for the quality control of the plant drug Harpagophytum procumbens (meaning dried roots of devil's claw) are available. However, there isn't specific monograph for herbal medicines/dosage forms containing $\mathrm{it}^{12}$. In the Brazilian Pharmacopeia the described method uses flow rate $1.5 \mathrm{~mL}$ in an isocratic system with water and methanol (50:50).
In addition, the method refers to the dosage in plant drug and not to the finished product ${ }^{12}$.

According to the Brazilian regulatory agency (Agência Nacional de Vigilância Sanitária Anvisa) when a monograph contemplates only analytical method for identification and quantification of markers for the vegetal drug, it is necessary to make adaptations and validate the method for the finished product ${ }^{13}$.

In the literature there are other published methods for harpagoside determination using isocratic or gradient elution with flow rate above $1 \mathrm{~mL} \mathrm{~min}{ }^{-1}$ and analysis time around $60 \mathrm{~min}^{14,15}$. The proposed method utilizes a flow rate of

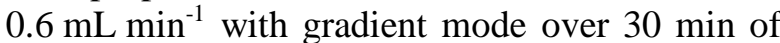
analysis. A quick method with greater solvent savings.

Therefore, this study aimed to develop and validate an analytical method using HPLC to contribute to the establishment of quality parameters for the finished product of this widely used medicinal plant, as well as to identify and quantify the harpagoside in commercial samples.

\section{Materials and methods}

\subsection{Standard, samples and reagents}

Harpagoside, considered chemical marker of the species and used for standardization of commercial products, was provided by SigmaAldrich. Three different brands of devil's claw tablets were obtained from pharmacies in Brasília, Brazil, named as brand A, B and C. About the concentration of dry extract of the roots of $H$. procumbens, the brands $\mathrm{A}, \mathrm{B}$, and $\mathrm{C}$ presented, respectively, 200, 400 and $450 \mathrm{mg}$. Regarding the total iridoid equivalents calculated as harpagoside, each tablet of the A, B and C brands had declared 10,20 and $18 \mathrm{mg}$, respectively. The solvents (HPLC grade) used in the assay were phosphoric acid (Sigma), acetonitrile (Tedia) and methanol (Tedia). The mobile phase was prepared with purified water produced in the Milli-Q system (Millipore).

\subsection{Sample and standard preparation}

Twenty tablets of each brand were macerated using mortar and pestle. A portion equivalent to $40 \mathrm{mg}$ of dry extract of the roots of $H$. procumbens was weighed, solubilized in methanol and prepared at the concentration of $4 \mathrm{mg} \mathrm{mL}^{-1}$ 
(this concentration is equivalent to $530 \mu \mathrm{g} \mathrm{mL}^{-1}$ of harpagoside). The resulting solution was filtered through a $0.45 \mu \mathrm{m}$ porosity disposable filter unit (Millipore Millex). The harpagoside standard was weighed and solubilized in methanol resulting in a concentration of $100 \mu \mathrm{g} \mathrm{mL}^{-1}$.

\subsection{Chromatographic conditions}

The LaChrom Elite chromatograph (Hitachi, Tokyo, Japan) was used for the analysis, contains an L2130 pump, L2200 injector, L2455 detector and L2300 column oven. The column used was the reverse phase C18e Purospher Star $(150 \times$ $4.6 \mathrm{~mm}, 5 \mu \mathrm{m}$, Merck, Germany). The temperature conditions, flow, injection volume and detection wavelength were $25{ }^{\circ} \mathrm{C}$, $0.6 \mathrm{~mL} \mathrm{~min}^{-1}, 10 \mu \mathrm{L}$ and $280 \mathrm{~nm}$, respectively. A gradient of $1 \%$ phosphoric acid and acetonitrile (Table 1) was used in the mobile phase. The total analysis time was $30 \mathrm{~min}$.

Table 1. Chromatographic conditions of the mobile phase gradient.

\begin{tabular}{|c|c|c|}
\hline $\begin{array}{c}\text { Time / } \\
\text { min }\end{array}$ & $\begin{array}{c}\text { Phosphoric acid 1\% / } \\
\text { \% }\end{array}$ & $\begin{array}{c}\text { Acetonitrile / } \\
\text { \% }\end{array}$ \\
\hline $0-20$ & 80 & 20 \\
\hline $20-21$ & 50 & 50 \\
\hline $21-25$ & 80 & 20 \\
$25-30$ & 80 & 20 \\
\hline
\end{tabular}

\subsection{Development and validation of the method by} HPLC-DAD

Leite et al.'s method (2014) ${ }^{16}$ was used with alterations to evaluate the finished product referring to devil's claw. The validation was carried out in accordance to the requirements of the Brazilian legislation, evaluating the parameters of linearity, limits of detection and quantification, precision, accuracy, selectivity and robustness ${ }^{17}$ and international guidelines for the industrial sector (International Conference on Harmonization $)^{18}$.

\subsubsection{Linearity}

Linearity was determined from three analytical curves with six concentrations of the harpagoside standard: 100.0, 200.0, 300.0, 500.0, 700.0 and $800.0 \mu \mathrm{g} \mathrm{mL} \mathrm{mL}^{-1}$. From these curves, linearity equations were obtained by linear regression. The software used to obtain these equations was
GraphPad Prism Version 6.01 2012. The proportional linear relation to the concentration and correlation coefficient should be higher than 0.9900 .

\subsubsection{Limit of Detection (LOD) and Quantification (LOQ)}

The slope (s) of the calibration curve and the standard deviation (SD) of the three calibration curves were considered, taking into account the intercept with the $\mathrm{Y}$-axis. These data are used in the equations to obtain LOD values and LOQ, that is, the smallest amount of marker that can be detected and quantified, respectively:

$\mathrm{LOD}=(\mathrm{SD} \times 3.3) / \mathrm{s} ; \quad \mathrm{LOQ}=(\mathrm{SD} \times 10) / \mathrm{s}$

\subsubsection{Precision}

According to the Brazilian legislation, precision must be expressed by repeatability, intermediate precision or reproducibility ${ }^{17}$. The repeatability determination was performed with six replicates with at $100 \%$ of the test concentration $\left(4 \mathrm{mg} \mathrm{mL}^{-1}\right.$, this concentration is equivalent to $530 \mu \mathrm{g} \mathrm{mL}^{-1}$ of harpagoside) and were analyzed on the same day. In the interday precision, three replicates with the same concentration $\left(4 \mathrm{mg} \mathrm{mL}^{-1}\right)$ were evaluated on three consecutive days.

\subsubsection{Accuracy}

In this study, the accuracy evaluation was done using the standard addition method, using nine determinations with three levels of theoretical concentration (low, medium and high) in triplicate for each level. In the case of finished product, according to the Brazilian legislation, if samples of all drug components are unavailable, analysis by the standard chemical addition method may be performed, in which know quantities of reference chemical are added to the solution of the finished prduct $^{17}$. The theoretical concentrations used were calculated at 80, 100 and 120\%; these concentrations were achieved using $500 \mu \mathrm{L}$ of the commercial $H$. procumbens sample with $500 \mu \mathrm{L}$ of the harpagoside standard. The harpagoside recovery percentage added to the sample was evaluated by the relation between the experimentally determined concentration and the corresponding theoretical concentration. 


\subsubsection{Selectivity}

The method ability to identify the harpagoside in the presence of impurities, degradation compounds or other components in the sample was assessed from induction of acidic and basic hydrolysis. The assay was done in triplicate, and the samples were solubilized using $1 \mathrm{~mol} \mathrm{~L}^{-1} \mathrm{HCl}$ for acid hydrolysis and $1 \mathrm{~mol} \mathrm{~L}^{-1} \mathrm{NaOH}$ for basic hydrolysis. After solubilization, the samples were placed in a water bath for $1 \mathrm{~h}$ at $60{ }^{\circ} \mathrm{C}$. After $1 \mathrm{~h}$, the samples were taken from the water bath and expected to reach room temperature to be neutralized with $1 \mathrm{~mol} \mathrm{~L}^{-1} \mathrm{HCl}$ or $1 \mathrm{~mol} \mathrm{~L}^{-1} \mathrm{NaOH}$ solution, regarding the sample, and diluted in methanol. The final concentration was $4 \mathrm{mg} \mathrm{mL}^{-1}$. The selectivity was evaluated by comparing the retention times and peak areas in the samples without hydrolysis and the samples submitted to the induction of acid and basic hydrolysis.

\subsubsection{Robustness}

The parameters chosen for the variation were temperature $\left(23-27^{\circ} \mathrm{C}\right)$, wavelength $(270-290 \mathrm{~nm})$ and flow of the mobile phase $\left(0.4-0.8 \mathrm{~mL} \mathrm{~min}{ }^{-1}\right)$. From these variations, the effects on the retention time and peak area were observed to evaluate if the method was robust.

\subsection{Identification and quantification of} harpagoside in commercial samples

The validated method was used to evaluate the presence of harpagoside, used to standardize commercial products, in the three brands of $H$. procumbens. The harpagoside identification in the samples was made comparing the peaks retention time and UV spectrum presented by the harpagoside standard with the standard peak of the samples. The harpagoside quantification was made from the linearity curve, in which the quantity of this marker could be calculated in the samples.

\subsection{Statistical analysis of data}

The GraphPad Prism 6.01 software. Data was used for the statistical analyzes of the data obtained in this study, and the results were expressed as the mean \pm standard deviation (SD).

\section{Results and discussion}

\subsection{Method validation}

The method was optimized for a $30 \mathrm{~min}$ analysis time (while the original method was 55 min) using a $\mathrm{C} 18 \mathrm{e}$ Purospher Star reverse phase column $(150 \times 4.6 \mathrm{~mm}, 5 \mu \mathrm{m})$. The mobile phase used was a gradient of $1 \%$ phosphoric acid and

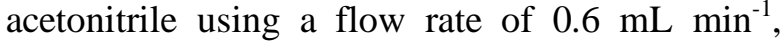
injection volume of $10 \mu \mathrm{L}$ and the chromatograms extracted at $280 \mathrm{~nm}$ wavelength.

Some parameters were evaluated for system suitability such as resolution $(3.90 \pm 0.03)$, retention time $(15.85 \pm 0.01)$, repeatability $(14,600,558 \pm 629,334)$, plate number $(13713 \pm$ $379)$ and tailing factor $(1.2 \pm 0.1)$.

\subsubsection{Linearity, limit of detection ( $L O D)$ and limit of quantification (LOQ)}

The method presented a linear response in the range of 100 to $800 \mu \mathrm{g} \mathrm{mL} \mathrm{m}^{-1}$ of concentrations. This correlation was made between the area of the peaks and their respective concentrations in triplicate. According to the Brazilian legislation, the correlation coefficient should be higher than 0.9900, and the method under study had a correlation coefficient of 0.9992 , according to the requirements, demonstrating the linearity of the method $^{15}$. From the linearity curve, LOD and LOQ were obtained: $1.12 \mu \mathrm{g} \mathrm{mL}^{-1}$ and $3.39 \mu \mathrm{g} \mathrm{mL}^{-1}$, respectively. The linearity and dispersion of residues graph are shown in Fig. 1. 

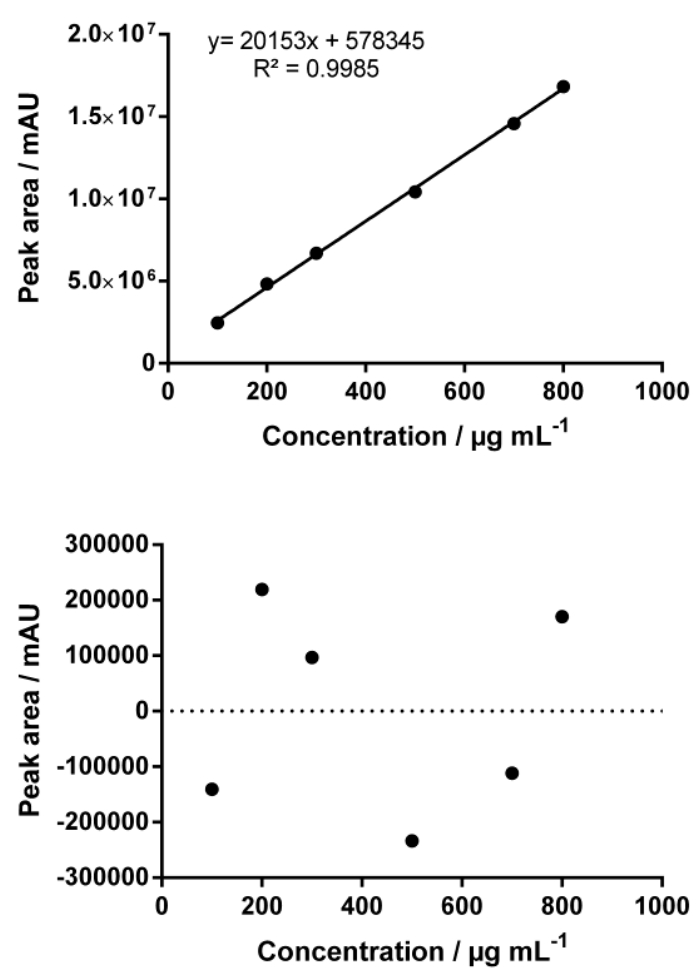

Figure 1. Linearity and dispersion of residues graph.

\subsubsection{Precision}

Regarding the precision of the results, the method demonstrated repeatability when presenting a standard deviation between the replicates of $4.31 \%$ for the intraday precision and $4.06 \%$ for the interday precision, not higher than $5 \%$ as recommended by the legislation ${ }^{17}$.

\subsubsection{Accuracy}

The accuracy of the method was evaluated by the standard addition method to the samples of known concentration. The objective of this method is to identify and quantify the harpagoside in commercial samples for that reason, the percentage of recovery the closer to $100 \%$, more accurate the method will be for this quantification. The obtained results showed this proximity, confirming that the method is accurate for the proposed objective, presenting a relative standard error of less than $5 \%$ (Table 2).

Table 2. Harpagoside recovery analysis after standard addition method.

\begin{tabular}{|c|c|c|c|}
\hline $\begin{array}{c}\text { Theoretical } \\
\text { concentration / } \\
\boldsymbol{\mu g} \mathbf{~ m L}^{-1}\end{array}$ & $\begin{array}{c}\text { Discovered } \\
\text { concentration / } \\
\boldsymbol{\mu g} \mathbf{~ m L}^{-1} \pm \mathbf{S D}\end{array}$ & $\begin{array}{c}\text { Recovery / } \\
\%\end{array}$ & $\begin{array}{c}\mathbf{E} / \\
\%\end{array}$ \\
\hline $100.869(80 \%)$ & $97.2 \pm 0.1$ & 96.33 & 3.67 \\
\hline $126.087(100 \%)$ & $120.0 \pm 0.3$ & 95.20 & 4.80 \\
\hline $151.304(120 \%)$ & $150 \pm 1$ & 99.02 & 0.98 \\
\hline
\end{tabular}

E: relative standard error

\subsubsection{Selectivity}

The purity of the peak of interest in the sample without acid or basic hydrolysis was pure $=1.00 \pm$ 0.00 . The method was selective to demonstrate that after induction of acidic and basic hydrolysis there was a complete degradation of the harpagoside peak and formation of degradation compounds (a degradation product peak formed with a purity of $0.995 \pm 0.005$ with retention time $19.870 \pm 0.007 \mathrm{~min}$ in basic hydrolysis and $0.94 \pm$ 0.04 with retention time $19.890 \pm 0.003 \mathrm{~min}$ in acid hydrolysis), and there was no co-elution of these with the peak of the marker. In this way, the method can identify and quantify the harpagoside in the presence of other substances.

\subsubsection{Robustness}

After the variations in wavelength and temperature parameters, no significant changes in the retention time and area of the harpagoside peak was observed. These results demonstrate that the proposed method is robust. However, regarding the flow variation, considerable changes in the retention time and area of the peak were observed, as can be seen in Table 3. From these results, the flow is a parameter that must be very well accompanied because the notorious influence on the separation of substances and especially on the purity of the harpagoside marker peak. 
Table 3. Parameters for analysis for robustness of the HPLC analytical method.

\begin{tabular}{|c|c|c|}
\hline Wavelength / nm & Peak area / mAU & Retention time / min \\
\hline 270 & $12,578,713 \pm 512,794$ & $15.82 \pm 0.01$ \\
\hline 280 & $14,070,719 \pm 585,792$ & $15.82 \pm 0.01$ \\
\hline 290 & $12,045,012 \pm 494,637$ & $15.82 \pm 0.01$ \\
\hline Temperature $/{ }^{\circ} \mathrm{C}$ & Peak area / mAU & Retention time / min \\
\hline 23 & $14,795,700 \pm 87,333$ & $15.802 \pm 0.01$ \\
\hline 25 & $14,853,562 \pm 133,593$ & $15.811 \pm 0.01$ \\
\hline 27 & $15,183,982 \pm 120,467$ & $15.804 \pm 0.01$ \\
\hline Flow $/ \mathrm{mL}$ min $^{-1}$ & Peak area (mAU) & Retention time (min.) \\
\hline 0.4 & $20,944,078 \pm 211,746$ & $20.19 \pm 0.01$ \\
\hline 0.6 & $14,122,976 \pm 174,969$ & $15.807 \pm 0.01$ \\
\hline 0.8 & $10,859,776 \pm 27,804$ & $13.445 \pm 0.01$ \\
\hline
\end{tabular}

\subsection{Identification and quantification of} harpagoside in commercial samples

The method developed and duly validated according to the legislation was used to identify and quantify harpagoside in the three commercial brands of $H$. procumbens available in Brasília/DF, Brazil. The chromatographic profiles were obtained using the proposed analytical method, and harpagoside was identified in the samples from the retention time and UV spectrum (Fig. 2).
All brands presented the harpagoside in its composition. The harpagoside was possible to quantify from the peak area of the marker, and all the brands had concentrations in inadequate amounts compared to the concentration declared in the package inserts (Table 4). The declared values compared to the amount found experimentally presented a variation in disagreement with the allowed of $\pm 15 \%{ }^{17}$ (Table 4).

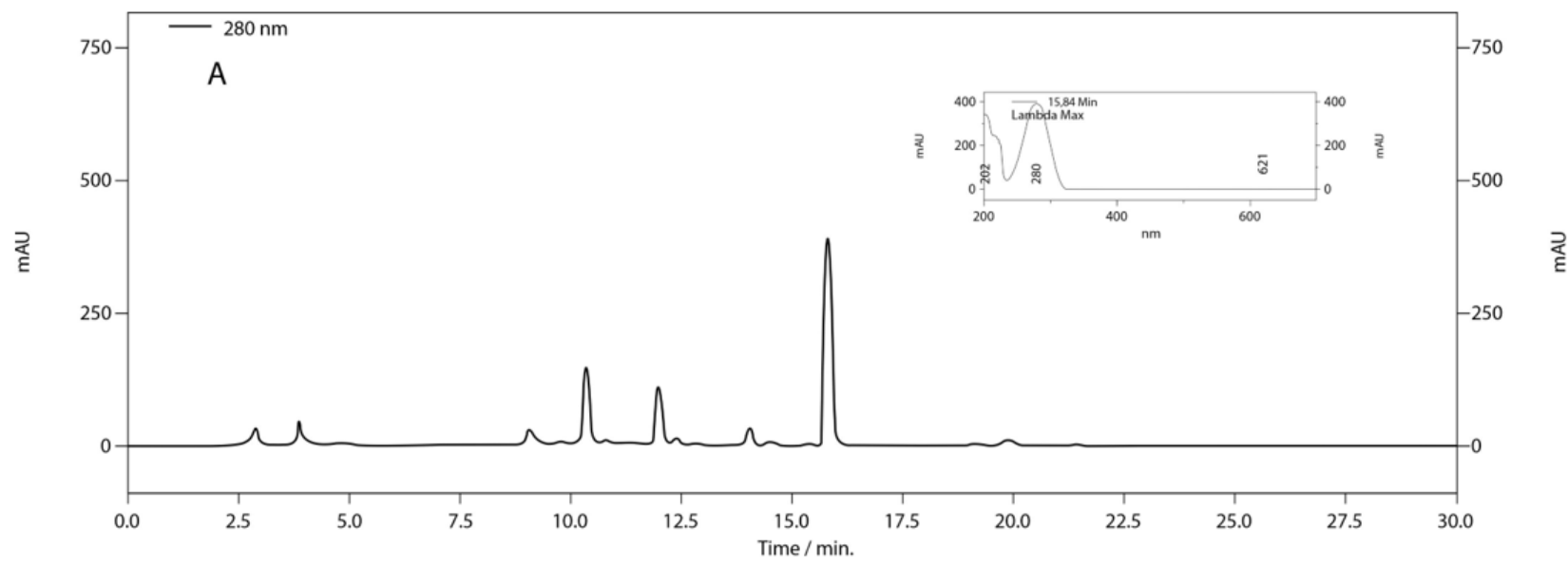



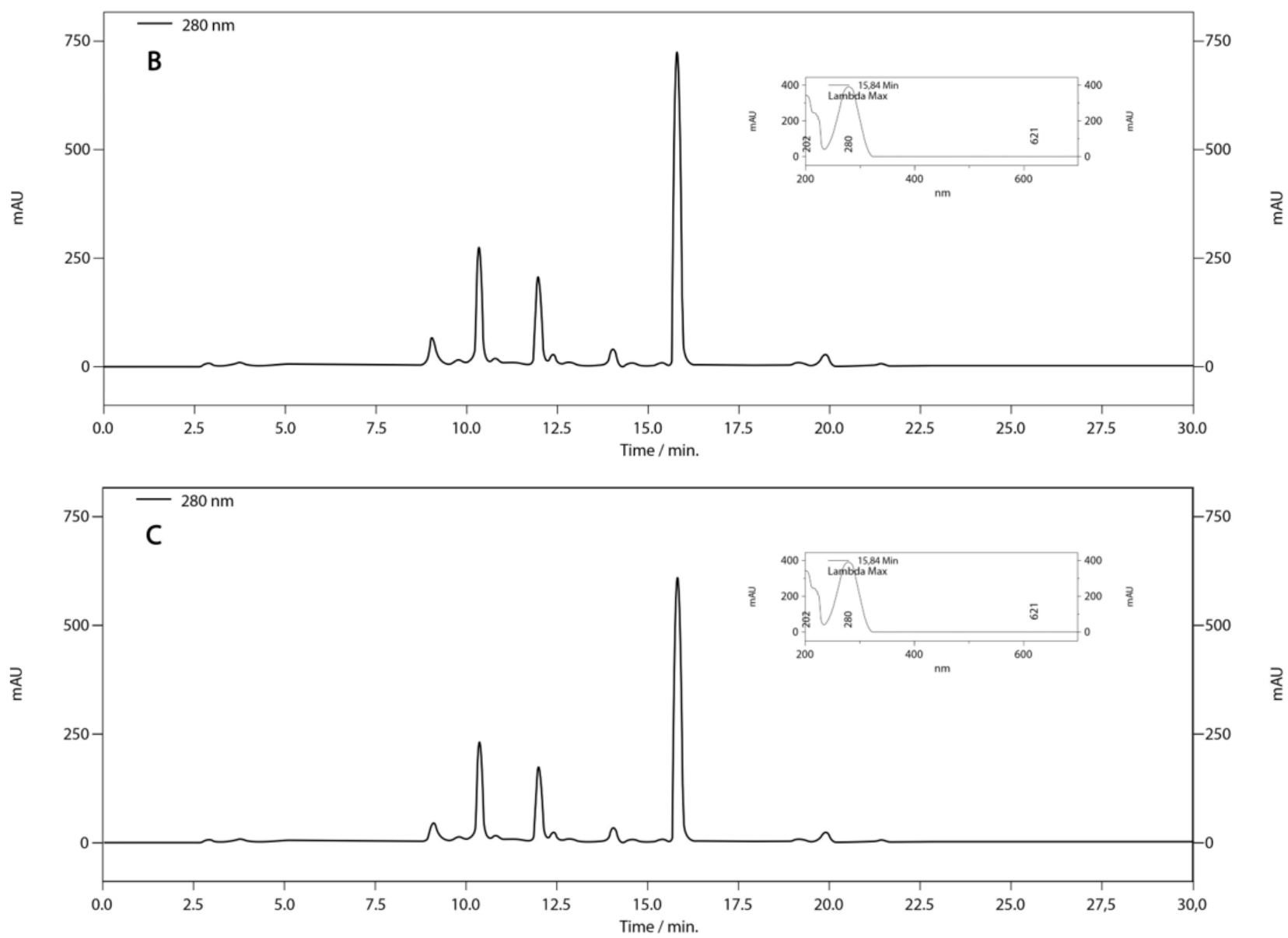

Figure 2. Chromatographic profiles of the brands A, B and C of the herbal medicine Harpagophytum procumbens obtained using HPLC-DAD with detection at $280 \mathrm{~nm}$. 1: Harpagoside.

Table 4. Harpagoside concentration in Harpagophytum procumbens DC tablets and experimentally determined daily dose compared to the concentration stated in the package inserts.

\begin{tabular}{|c|c|c|c|c|}
\hline \multirow{2}{*}{ Brand } & \multicolumn{2}{|c|}{$\begin{array}{c}\text { Concentration of harpagoside / } \mathbf{~ m g ~ m L} \mathbf{~ m}^{-1} \\
\text { Declarated }\end{array}$} & $\begin{array}{c}\text { *Variation of } \\
\text { harpagoside } \\
\text { concentration / \% }\end{array}$ & $\begin{array}{c}* * \text { Daily dose of } \\
\text { harpagoside / mg }\end{array}$ \\
\hline A & 0.05 & $0.0290 \pm 0.0009$ & -42.00 & 17.40 \\
\hline B & 0.05 & $0.064 \pm 0.001$ & +28.00 & 76.80 \\
\hline C & 0.04 & $0.0510 \pm 0.0002$ & +27.50 & 68.70 \\
\hline
\end{tabular}

* Variation allowed by the Brazilian legislation is $\pm 15 \%{ }^{13}$

** Daily dose recommended by the Brazilian legislation is 30 to $100 \mathrm{mg}^{17}$

For all brands, the suggested posology was one tablet three times a day. To find the daily doses, a relation between the declared value and the experimentally determined harpagoside content was done. The results showed that, regarding the daily posology, all brands were out the specifications determined by the Brazilian legislation (30 to $100 \mathrm{mg}$ ) ${ }^{13}$ (Table 4). This fact can imply in possible toxic effects due to an overdosage, considering the active principle of herbal medicines presents pharmacological action $^{19}$. Therefore, these results suggest a serious health risk due to therapeutic failure or toxicity. One study demonstrated that the majority of patients responded more to treatment using the highest daily dose of harpagoside (100 mg), as well as the adverse events are predictable and dose-dependent. The active principle is bitter and stimulates the production of gastrointestinal juice. Therefore, adverse events are mainly gastrointestinal $^{20}$. 


\section{Conclusion}

The proposed method in this study for the identification and quantification of harpagoside in the herbal medicine devil's claw was efficient and quick to evaluate the quality of these products to ensure authenticity, credibility, safety and therapeutic efficacy. The obtained results emphasize the importance of quality control since we observed, in all three medicinal products, significant variations in the quantity of harpagoside in comparison to the value declared in the registry of these products.

\section{Acknowledgments}

The authors greatly acknowledge Research program for the SUS: shared management in health PPSUS - FAP/DF/SESDF/MS/CNPQ (Grant number 193.000.860/2014), National Council for Scientific and Technological Development (CNPq), Foundation for Research Support of the Federal District (FAPDF), Coordination of Improvement of Higher Education Personnel (CAPES) and University of Brasília (DPP/UnB) for the financial support to carry out this research.

\section{References}

[1] Terra-Junior, O. N., Maldonado, J. V., Arnobio, A., Estudo do desempenho comercial dos insumos farmacêuticos vegetais sob a ótica do Comércio Exterior, Revista Fitos 9 (3) (2015) 233-246. https://www.arca.fiocruz.br/handle/icict/19237.

[2] Brasil, Ministério da Saúde. Política Nacional de Plantas Medicinais e Fitoterápicos, Brasília: Ministério da Saúde (2006). http://bvsms.saude.gov.br/bvs/publicacoes/politica_nac ional_fitoterapicos.pdf.

[3] Moura, M. G., Lopes, L. C., Biavatti, M. W., Busse, J. W., Wang, L., Kennedy, S. A., Bhatnaga, N., Bergamaschi, C. C., Brazilian oral herbal medication of osteoarthritis: a systematic review protocol, Systematic $\begin{array}{lllll}\text { Reviews } & 5 & \text { (86) } & \text { (2016) } & 1-7 .\end{array}$ https://doi.org/10.1186/s13643-016-0261-1.

[4] Tropicos. Missouri Botanical Garden, Harpagophytum procumbens, Tropicos (2017). http://www.tropicos.org/Name/24300038.
[5] Grant, L., McBean, D. E., Fyfe, L., Warnock, A. M., A review of the biological and potencial therapeutic actions of Harpagophytum procumbens, Phytotherapy Research 21 (3) (2007) 199-209. https://doi.org/10.1002/ptr.2029.

[6] Mncwangi, N., Chen, W., Vermaak, I., Viljoen, A. M., Gericke, N., Devil's Claw - A review of the ethnobotany, phytochemistry and biological activity of Harpagophytum procumbens, Journal of $\begin{array}{lllll}\text { Ethnopharmacology } & 143 & \text { (3) (2012) 755-771. }\end{array}$ https://doi.org/10.1016/j.jep.2012.08.013.

[7] Georgiev, M. I., Ivanovska, N., Alipieva, K., Dimitrova, P., Verpoorte, R., Harpagoside: from Kalahari Desert to pharmacy shelf, Phytochemistry 92 (2013) 8-15. https://doi.org/10.1016/j.phytochem.2013.04.009.

[8] Oliveira, E. M. A., Maywald, P. G., Rosa, G. A. A., Distribuição de plantas medicinais e fitoterápicos através do SUS, E-RAC 3 (1) (2013) 3-19. http://www.computacao.unitri.edu.br/erac/index.php/erac/article/view/141.

[9] Souza-Moreira, T. M., Salgado, H. R. N., Pietro, R. C. L. R., O Brasil no contexto de controle de qualidade e plantas medicinais, Revista Brasileira de

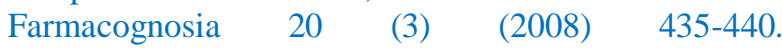
https://doi.org/10.1590/S0102-695X2010000300023.

[10] Tistaert, C., Dejaegher, B., Heyden, Y. V., Chromatographic separation techniques and data handling methods for herbal fingerprints: A review, Analytica Chimica Acta 690 (2) (2011) 148-161. https://doi.org/10.1016/j.aca.2011.02.023.

[11] Veiga Junior, V. F., Mello, J. C. P., As monografias sobre plantas medicinais, Revista Brasileira de Farmacognosia 18 (3) (2008) 464-471. https://doi.org/10.1590/S0102-695X2008000300022.

[12] Brasil, Agência Nacional de Vigilância Sanitária, Farmacopeia Brasileira, Brasília: Agência Nacional de Vigilância Sanitária 5 (Suppl. 2) (2017) 1-1016. http://portal.anvisa.gov.br/documents/33832/259143/Se gundo+Suplemento+FB+5/9cfb1239-875c-4a77-8741b59416684d29.

[13] Brasil, Agência Nacional de Vigilância Sanitária, Instrução normativa $\mathrm{n}^{\circ}$ 4, de 18 de junho de 2014, Determina a publicação do Guia de orientação para registro de medicamento fitoterápico e registro e notificação de produto tradicional fitoterápico, Diário Oficial da União (2014). http://portal.anvisa.gov.br/documents/33836/2501251/ Guia\%2Bfinal\%2Bdicol\%2B180614+\%282\%29.pdf/f4 00c535-e803-4911-9ef8-100c0c2bb3c6. 
[14] Nalluri, B. N., Kumar, S., Characterization and estimation of harpagoside in dried root extract and oral powder formulations of Harpagophytum procumbens by validated RP-HPLC-PDA Method, Journal of Drug Delivery and Therapeutics 9 (2) (2019) 38-46. http://jddtonline.info/index.php/jddt/article/view/2459/ 1788.

[15] Avato, P., Argentieri, M. P., Quality Assessment of Comercial Spagyric Tinctures of Harpagophytum procumbens and Their antioxidant properties, Molecules, $24 \quad$ (12) (2019) 2-15. https://doi.org/10.3390/molecules24122251.

[16] Leite, C. F. M., Leite, B. H. M., Barros, I. M. C., Gomes, S. M., Fagg, C. W., Simeoni, L. A., Silveira, D., Fonseca, Y. M., Determination of rutin in Erythroxylum suberosum extract by liquid chromatography: applicability instandardization of herbs and stability studies, Boletín Latinoamericano y del Caribe de Plantas Medicinales y Aromáticas 13 (2) (2014) 135-143.

[17] Brasil, Agência Nacional de Vigilância Sanitária. Resolução da Diretoria Colegiada n ${ }^{\circ} 166$, de 24 de julho de 2017, Dispõe sobre a validação de métodos analíticos e dá outras providências, Diário Oficial da União (2017). http://www.in.gov.br/materia//asset_publisher/Kujrw0TZC2Mb/content/id/19194581 /do1-2017-07-25-resolucao-rdc-n-166-de-24-de-julhode-2017-19194412.

[18] European Medicines Agency. ICH Topic Q2B; Note for guidelines on Validation of Analytical Procedures: Text and Methodology, European Medicines Agency (1995). https://www.ema.europa.eu/en/documents/scientificguideline/ich-q-2-r1-validation-analytical-procedurestext-methodology-step-5_en.pdf.

[19] Bettega, P. V. C., Czlusniak, G. R., Piva, R., Namba, E. L., Ribas, C. R., Grégio, A. M. T., Rosa, E. A. R., Fitoterapia: dos canteiros ao balcão da farmácia, Archives of Oral Research 7 (1) (2011) 89-97. https://periodicos.pucpr.br/index.php/oralresearch/articl e/view/23149/22243.

[20] Vlachojannis, J., Roufogalis, B. D., Chrubasik, S., Systematic review on the safety of Harpagophytum preparations for osteoarthritic and low back pain, Phytotherapy Research 22 (2) (2008) 149-152. https://doi.org/10.1002/ptr.2314. 